associations appear independent of gut inflammation and both NSAID and immunomodulatory treatment. This provides further evidence for an important link between disturbances in gastrointestinal homeostasis and axSpA manifestations, and implies that gut dysbiosis may be a novel biomarker for severe disease.

Table 1.

\begin{tabular}{|c|c|c|c|c|}
\hline & All patients $n=132$ & $\begin{array}{l}\text { Nr-axSpA } \\
\mathrm{n}=44\end{array}$ & $\begin{array}{l}\text { AS } \\
n=88\end{array}$ & $\begin{array}{l}\text { Controls } \\
\mathrm{n}=46\end{array}$ \\
\hline Male sex, n (\%) & $72(55)$ & $17(39)$ & $55(63)$ & $23(50)$ \\
\hline Age, y & $53(13)$ & $48(12)$ & $55(13)$ & 51 (14) \\
\hline Symptom duration, $\mathrm{y}$ & $26(14)$ & $21(11)$ & 28 (14) & \\
\hline Body mass index, $\mathrm{kg} / \mathrm{m}^{2}$ & $27(4.3)$ & $27(4.2)$ & $27(4.3)$ & $25(3.3)$ \\
\hline $\begin{array}{l}\text { Smoking ever, n (\%) } \\
\text { CRP, mg/L }\end{array}$ & $\begin{array}{l}43(33) \\
3.7(5.3)\end{array}$ & $\begin{array}{l}9(20) \\
2.3(2.4)\end{array}$ & $\begin{array}{l}34(39) \\
4.3(6.1)\end{array}$ & \\
\hline F-Calprotectin $\geq 50 \mathrm{mg} / \mathrm{kg}, \mathrm{n}(\%)$ & $46(35)$ & $12(27)$ & 34 (39) & \\
\hline Evaluator's global, $0-4$, median (IQR) & $1(0-1)$ & $1(0-1)^{\prime}$ & $1(0-1)^{\prime}$ & \\
\hline ASDAS-CRP & $1.8(0.9)$ & $1.9(0.9)$ & $1.8(0.9)$ & \\
\hline $\begin{array}{l}\text { BASDAI } \\
\text { BASFI }\end{array}$ & $\begin{array}{l}3.1(2.2) \\
2.0(2.1)\end{array}$ & $\begin{array}{l}3.3(1.9) \\
2.0(1.7)\end{array}$ & $\begin{array}{ll}3.0(2.4) \\
2.1(2 ?)\end{array}$ & \\
\hline VAS pain, $\mathrm{cm}$ & $3.3(2.5)$ & $3.4(2.2)$ & $3.2(2.7)$ & \\
\hline IBS symptoms, n (\%) & $43(33)$ & $15(34)$ & $28(32)$ & \\
\hline ASAS 3-month NSAÍD score & $37(44)$ & $36(44)$ & $37(44)$ & \\
\hline Ongoing csDMARD, $n(\%)$ & $24(18)$ & $9(20)$ & 15 (17) & \\
\hline Ongoing bDMARD, n (\%) & $56(42)$ & $19(43)$ & $37(42)$ & \\
\hline
\end{tabular}

Mean (SD) unless otherwise specified. y, years; IBS, irritable bowel syndrome

Disclosure of Interests: Jonas Sagard: None declared, Tor Olofsson Consultant of: Eli Lilly, Merck Sharp \& Dohme, Elisabeth Mogard: None declared, Jan Marsal Consultant of: AbbVie, Bristol-Myers Squibb, EuroDiagnostica, Ferring, Hospira, Janssen-Cilag, Merck, Sharp \& Dohme (MSD), Otsuka, Pfizer, Sandoz, Takeda, Tillotts, UCB Pharma, Grant/research support from: AbbVie, Ferring, and Pfizer, Kristofer Andréasson: None declared, Mats Geijer Speakers bureau: UCB Pharma, AbbVie, Novartis, Pfizer, Lars Erik Kristensen Speakers bureau: Pfizer, AbbVie, Amgen, UCB, Celegene, BMS, MSD, Novartis, Eli Lilly, Janssen pharmaceuticals, Consultant of: Pfizer, AbbVie, Amgen, UCB, Celegene, BMS, MSD, Novartis, Eli Lilly, Janssen pharmaceuticals, Elisabet Lindqvist: None declared, Johan K Wallman Consultant of: Celgene, Eli Lilly, Novartis

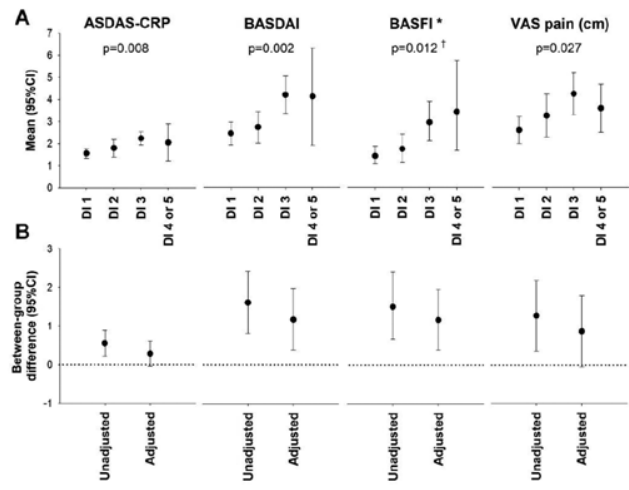

Figure - A: AxSpA outcomes in relation to Dysbiosis Index (Dl, a measure of gut microbiots aberration, with $\geq 3$ denoting dysbiosis). P-values for overall between group differences (One-way ANOVA; + Kruskal-Wallis test). B: Between-group differences (unadjusted and adjusted) in axSpA outcomes between patients with gut dysbiosis (DIZ3) vs. those without. "Bootstrapped $95 \%$ Cl:s.

DOI: 10.1136/annrheumdis-2021-eular.472

\section{POS0238 $\quad$ SICK LEAVE AND ITS PREDICTORS IN EARLY AXIAL SPONDYLOARTHRITIS: THE ROLE OF CLINICAL AND SOCIOECONOMIC FACTORS. FIVE-YEAR DATA FROM THE DESIR COHORT}

E. Nikiphorou ${ }^{1,2}$, P. Carvalho ${ }^{3,4,5}$, A. Boonen ${ }^{6,7}$, B. Fautrel ${ }^{8}$, P. Richette ${ }^{9}$, P. M. Machado ${ }^{10}$ D. Van der Heijde ${ }^{11}$, R. B. M. Landewé ${ }^{12,13}$, S. Ramiro ${ }^{11,12}$. ${ }^{1}$ King's College London, Centre for Rheumatic Diseases, London, United Kingdom; ${ }^{2}$ King's College Hospital NHS Trust, Rheumatology, London, United Kingdom; ${ }^{3}$ Centro Hospitalar Universitário do Algarve, Rheumatology, Faro, Portugal; ${ }^{4}$ Centro Académico Médico de Lisboa, Rheumatology, Lisboa, Portugal; ${ }^{5}$ Algarve Biomedical Center, Rheumatology, Faro, Portugal; ${ }^{6}$ Maastricht University Medical Center and Care and Public Health Research Institute (CAPHRI), Rheumatology, Maastricht, Netherlands; ${ }^{7}$ Academic Hospital Maastricht, Internal Medicine, Div. of Rheumatology, Maastricht, Netherlands; ${ }^{8}$ Sorbonne University - Assistance Publique Hopitaux de Paris, Pitie Salpetriere Hospital, Pierre Louis Institute for Epidemiology and Public Health, INSERM UMRS 1136, PEPITES Teams, Rheumatology, Paris, France; ${ }^{9}$ Université de Paris, Hopital Lariboisière, Rheumatology, Paris, France; ${ }^{10}$ University College London, Centre for Rheumatology, London, United Kingdom; ${ }^{11}$ Leiden University Medical Center (LUMC), Rheumatology, Leiden, Netherlands; ${ }^{12}$ Zuyderland MC, Rheumatology, Heerlen, Netherlands;

${ }^{13}$ Amsterdam University Medical Center, Rheumatology,Amsterdam, Netherlands

Background: Sick leave (SL) represents an often poorly studied adverse work outcome especially in early axSpA, with speculation around the potential role of clinical and socioeconomic (SE) factors.

Objectives: To investigate the occurrence of SL and the impact of clinical and SE factors on SL in early axSpA.
Methods: Patients with a clinical diagnosis of axSpA from the DESIR cohort up to 5 years of follow-up (6-month visits in the first 2 years, followed by annual visits) were studied. Time to SL and potential baseline and time-varying predictors were explored, with a focus on SE variables: age, gender, smoking status since last visit, ethnicity (Caucasian vs other), job type based on 'collar' (blue vs white), educational status (low vs high -university), mar ital status (married vs not) and parental status (number of children); and clinical factors including disease activity (ASDAS/BASDAI), function (BASFI), mobility (BASMI), at each time point. The incidence of SL was calculated as the number of SL events over the total number of person-days under observation. Univariable analyses, followed by collinearity and interaction tests, guided subsequent multivariable Cox survival model building.

Results: In total, 704 axSpA patients with work-related data were included in this study: mean (SD) age 33.8 (8.6); 46\% male. At baseline, $80 \%$ of patients were employed; of these, $5.7 \%$ reported being on SL, with people shifting in and out of different work states over time. The distribution of first and recurrent SL episodes over time is shown in the fig ure 1. The incidence of SL amongst those at risk ( $n=620,88 \%)$ and across the five years of DESIR was $0.05(95 \% \mathrm{Cl} 0.03,0.06)$ per 1000 days calculated in a total of 913,559 observed person-days. In survival analyses, $7 \%(n=43)$ of those at risk developed SL at some point. Mean (SD) time to SL was 806 (595) days (min 175, max 2021 days). In people who developed SL, 25\% did so at 364 days; $50 \%$ and $75 \%$ at 545 and 1172 days, respectively. Significant differences were seen between baseline socio-demographic, clinical variables and treatment in patients who developed SL at any point, compared to those who did not. In multivariable models (Table 1) older age, higher disease activity, smoking and use of TNFi, the latter likely a proxy to worse disease, were all significantly associated with more SL. Male gender and higher education were associated with less SL. There were no relevant interactions between SE factors and clinical variables.

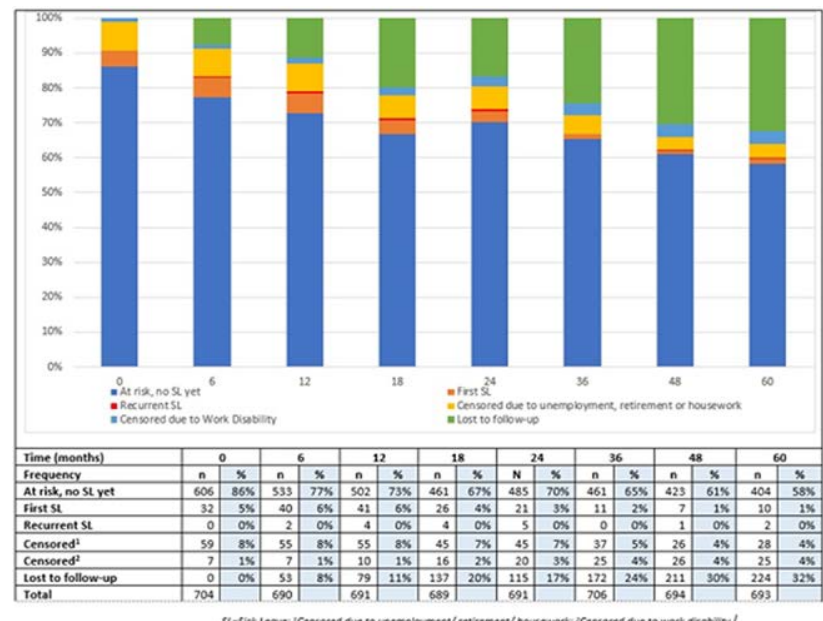

Figure 1. Distribution of first and recurrent sick leave episodes over time in the study population at risk.

Table 1. Univariable and multivariable model analyses with Sick Leave as outcome.

\begin{tabular}{lll}
\hline Type of analysis & \multicolumn{1}{c}{ Univariable analysis } & Multivariable model \\
\cline { 2 - 3 } Explanatory variables & $\mathrm{HR}(95 \% \mathrm{Cl})$ & $\mathrm{HR}(95 \% \mathrm{Cl})(\mathrm{N}=614)$ \\
Age & $1.04(1.01,1.08)$ & $1.05(1.01,1.09)$ \\
Male gender & $0.37(0.19,0.74)$ & $0.41(0.20,0.86)$ \\
High education & $0.33(0.17,0.61)$ & $0.48(0.24,0.95)$ \\
Marital status & $2.44(1.12,5.27)$ & $\mathrm{NS}$ \\
ASDAS (CRP) & $1.83(1.34,2.50)$ & $1.49(1.04,2.13)$ \\
BASFI, 0-10 & $1.24(1.09,1.40)$ & $*$ \\
BASMl, 0-10 & $1.76(1.31,2.38)$ & $*$ \\
Comorbidity count & $1.77(1.22,2.57)$ & $\mathrm{NS}$ \\
HLA-B27 positive & $0.51(0.28,0.93)$ & $\mathrm{NS}$ \\
Smoking (current vs not) & $2.40(1.31,4.37)$ & $2.55(1.32,4.91)$ \\
NSAID score last week, $0-400$ & $1.01(1.00,1.01)$ & $\mathrm{NS}$ \\
Oral Corticosteroid use (vs no) & $3.90(1.80,8.46)$ & $\mathrm{NS}$ \\
TNF use & $2.86(1.55,5.28)$ & $2.41(1.27,4.58)$ \\
\hline
\end{tabular}

*Variables tested in models separate from ASDAS. NS=Not significant in multivariable model.

Conclusion: In this early axSpA cohort of young, working-age individuals, older age and worse disease activity were associated with more SL, whereas male gender and highe education were associated with less SL. The findings suggest a role of SE factors such as gender and level of education in adverse work outcomes, alongside active disease.

Disclosure of Interests: None declared

DOI: 10.1136/annrheumdis-2021-eular.723

\section{POS0239 \\ ROOT JOINT INVOLVEMENT IN SPONDYLOARTHRITIS: A POST-HOC ANALYSIS FROM THE INTERNATIONAL ASAS-PERSPA STUDY}

N. Ziade ${ }^{1}$, J. El-Hajj ${ }^{2}$, J. Rassi ${ }^{3,4}$, S. Hlais ${ }^{5,6}$, C. López-Medina ${ }^{7,8}$, S. Gamal ${ }^{9}$

B. Zorkany ${ }^{9,10}$, M. Dougados ${ }^{7}$, X. Baraliakos ${ }^{11}$. ${ }^{1}$ Saint-Joseph University,

Rheumatology, Beirut, Lebanon; ${ }^{2}$ Saint-Joseph University, Medicine, Beirut, Lebanon;

${ }^{3}$ Saint-Joseph University, Surgery, Beirut, Lebanon; ${ }^{4}$ Hotel-Dieu de France, Orthopedic Surgery, Beirut, Lebanon; ${ }^{5}$ Saint-Joseph University, Family Medicine, Beirut, Lebanon; 